\title{
Estimation of the mating system in a fungal pathogen Crumenulopsis sororia (Karst.) Groves using isozyme markers
}

\author{
R. A. Ennos and \\ K. W. Swales
}

\author{
Department of Forestry and Natural Resources, \\ University of Edinburgh, The King's Buildings, \\ Mayfield Road, Edinburgh EH9 3JU, U.K.
}

The mating system of the ascomycete forest pathogen Crumenulopsis sororia was investigated using naturally occurring isozyme genetic markers and appropriate genetic models. Mating was found to occur exclusively through outcrossing. For 8 of the 25 apothecia scored, more than one male parent was involved in giving rise to ascogenous hyphae. Substantial subdivision occurs within the population which is composed of genetically differentiated subpopulations occupying discrete lesions on host trees.

\section{INTRODUCTION}

Although fungal pathogens are of considerable economic importance in agriculture and forestry, we know little about their population genetics and evolution. Some background information on levels of genetic variability in their saprotrophic relatives has proved valuable (Jinks et al., 1966; Brasier, 1970; Speith, 1975; Perkins et al., 1976). In addition we have data on variation for sexual incompatability loci (Burnett, 1965; Stenlid, 1985), virulence races (Roelfs and Groth, 1980), and vegetative compatibility (Anagnostakis, 1977, 1982a; Rayner and Turton, 1982; Brasier, 1984) in a limited range of parasitic species. More recent analyses of isozyme variation have provided information on the origins and genetic structure of a handful of economically important pathogen populations (Burdon and Marshall, 1981, 1983; Burdon et al., 1981, 1982; Bernier et al., 1983; Old et al., 1984; Burdon and Roelfs, 1985a, 1985b; Newton and Caten, 1985). Despite these efforts, however, we remain ignorant of many aspects of the genetics of fungal pathogen populations.

One topic on which much further work is required is that of mating systems. Our present knowledge of fungal mating systems relies heavily on observations of sexual reproductive behaviour in culture. Species are broadly classified into those which are able to reproduce without the need for cross-fertilisation (homothallic), and those which must be fertilised by a compatible genotype for complete sexual development (heterothallic) (Whitehouse, 1949; Burnett, 1956; Raper, 1966). This classification, while useful as a first step, is wholly inadequate for describing fungal mating systems in a quantitative manner and has two serious drawbacks. In the first place it is applicable only to those species which can be induced to fruit in culture. Secondly, it can only provide information on the ability of a species to self-fertilise, and gives no indication of the extent to which this ability is practiced in the natural population. In the light of these deficiencies it is clear that a new approach for the quantitative estimation of fungal mating systems is required.

In this paper we describe a method for investigating the mating system of an ascomycete forest pathogen, Crumenulopsis sororia, using a modification of techniques originally developed for elucidating the mating systems of higher plants (Clegg, 1980; Brown et al., 1985). Families of isolates are obtained from fruiting bodies sampled from a single natural population. These isolates are scored for their genotype at a number of polymorphic isozyme loci to provide family-structured genotypic data. Simple genetic models are then developed which allow us to describe the mating process in a quantitative manner. This approach obviates fruiting induction in culture, and at the same time provides a description of the mating process as it occurs in the natural population. Information on the genetic structure of the pathogen population can also be gleaned from the isozyme data. 


\section{MATERIALS AND METHODS}

\section{Study organism}

C. sororia is a discomycete fungus which grows as a facultative wound pathogen, principally on Scots pine, Pinus sylvestris (van Vloten and Gremmen, 1953; Batko and Pawsey, 1964; Groves, 1969). Infection of shoots and stems takes place by means of airborne ascospores. After germination the haploid mycelium invades phloem, cambium anc xylem and gives rise to a perennial, resin soaked canker (Manap and Hayes, 1971). Following fertilisation by microconidia a disc-shaped apothecium develops which measures $1-2 \mathrm{~mm}$ in diameter. Each apothecium consists of maternal haploid supporting tissues within which are found the dikariotic ascogenous hyphae which have resulted from fertilisation. Ascogenous hyphae give rise to asci and haploid ascospores in the normal manner. Ascospores are released in spring and summer following periods of wet weather (Hayes 1975).

\section{Collection of material}

A single lesion was collected from each of nine infected trees of Scots pine in the Black Wood of Rannoch, Perthshire (NN 565560). From 1-5 apothecia were removed from each lesion and mounted on wax on the upper lid of a petri dish containing malt extract agar (MEA) (20 g malt extract, $20 \mathrm{~g}$ agar/l). $1.5 \mathrm{ml}$ of sterile distilled water were dispensed onto the agar. Ascospores released into the water over a 2 day period were dispersed by gently tipping the dish. After ascospores had germinated, 20-24 single ascospore isolates were picked off the plate under a dissecting microscope. Isolates were grown up on split pine twigs which had been autoclaved at $120^{\circ} \mathrm{C}$ for 20 minutes and placed on the surface of an MEA plate. Two weeks after inoculation twigs were removed from the MEA plate and stored at $-20^{\circ} \mathrm{C}$ in sterile glass bottles. In certain cases it was also possible to obtain isolations from the wall of the apothecium which is composed of haploid maternal tissue. These isolates were stored frozen on wood as described above.

\section{Isozyme analysis}

Mycelium samples of $1 \mathrm{~mm}^{3}$, taken from actively growing cultures on MEA, were transferred to $50 \mathrm{ml}$ flasks containing $10 \mathrm{ml}$ of sterile liquid medium ( $10 \mathrm{~g}$ glutamic acid, $10 \mathrm{~g}$ glucose, $2 \mathrm{~g}$ yeast extract, $1 \mathrm{~g} \mathrm{KH}_{2} \mathrm{PO}_{4}, 0.2 \mathrm{~g} \mathrm{MgSO}_{4} \cdot 7 \mathrm{H}_{2} \mathrm{O}, 0.02 \mathrm{~g}$
$\mathrm{FeCl}_{3}, 880 \mu \mathrm{g} \mathrm{ZnSO} \mathrm{Zn}_{4} 7 \mathrm{H}_{2} \mathrm{O}, 400 \mu \mathrm{g} \mathrm{MnSO}_{4} \cdot 4 \mathrm{H}_{2} \mathrm{O}$ in 11 distilled water $p \mathrm{H} \mathrm{6.0)}$ ). After 2 weeks growth at $20^{\circ} \mathrm{C}$ on an orbital incubator at 100 r.p.m. the mycelium was harvested, blotted dry, and stored at $-20^{\circ} \mathrm{C}$.

For isozyme analysis $15 \mathrm{mg}$ samples of mycelium were ground over ice in 2-3 drops of extraction buffer $\left(1.36 \mathrm{~g} \mathrm{KH}_{2} \mathrm{PO}_{4}, 3.6 \mathrm{~g}\right.$ cysteine, $3.36 \mathrm{~g}$ EDTA, $136 \mathrm{~g}$ sucrose, $24 \mathrm{~g}$ tris, $3.8 \mathrm{~g}$ sodium

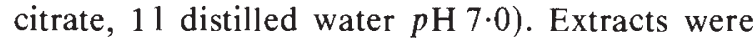
absorbed on filter paper wicks and run for 4.5 hours on starch gels $(110 \mathrm{~g} / 1)$. Four enzyme systems were scored; Phosphoglucose isomerase (PG1; E.C.5.3.1.9), Phosphoglucomutase (PGM; E.C.2.7.5.1), Leucine aminopeptidase (LAP; E.C.3.4.11.1), and Glutamate oxaloacetate transaminase (GOT; E.C.2.6.1.1). Formulae for 11 volumes of each electrophoretic buffer system were: $1.08 \mathrm{~g}$ citric acid, $5.59 \mathrm{~g}$ tris, $0.12 \mathrm{~g}$ $\mathrm{LiOH} \cdot \mathrm{H}_{2} \mathrm{O}, 1 \cdot 39 \mathrm{~g}$ boric acid $p \mathrm{H} 8 \cdot 2(\mathrm{gel}), 1 \cdot 2 \mathrm{~g}$ $\mathrm{LiOH} \cdot \mathrm{H}_{2} \mathrm{O}, 11.89 \mathrm{~g}$ boric acid $p \mathrm{H} 8.1$ (bridge) for PGI and LAP; $3.52 \mathrm{~g}$ glycine, $0.19 \mathrm{~g}$ EDTA $p \mathrm{H}$ 8.8 (gel), $7.03 \mathrm{~g}$ glycine, $0.37 \mathrm{~g}$ EDTA $p \mathrm{H} 8.8$ (bridge) for PGM; $2.52 \mathrm{~g}$ dl histidine $\mathrm{HCl}, 0.375 \mathrm{~g}$ citric acid $p \mathrm{H} 6.5$ (gel), $16.35 \mathrm{~g}$ tris, $9 \mathrm{~g}$ citric acid $p \mathrm{H} 6.5$ (bridge) for GOT. Before staining, both the LAP and GOT gels were placed in soaking solutions for 20 minutes $(112 \mathrm{~g}$ tris/1 for LAP, and $30.9 \mathrm{~g}$ boric acid, $1 \mathrm{~g} \mathrm{MgCl}_{2} / \mathrm{l}$ for GOT). Staining procedures were modified after Vallejos (1983).

\section{RESULTS AND ANALYSIS}

\section{Isozyme variation}

Variation was found at all four loci. The range of banding patterns for single ascospore isolates, and their inferred genotypes are given in fig. 1. Although it has not yet been possible to conduct controlled crosses between isozyme variants it seems reasonable to assume that the differences in isozyme mobility are determined by variation at single genetic loci. This assumption is supported by the fact that the results for any one isolate are absolutely repeatable, and by the patterns of segregation from apothecia obtained in the natural population. For all four enzyme systems only two alleles were found at the putative genetic loci. In subsequent mating models therefore it is reasonable to assume diallelism.

\section{Mating system}

The numbers of progeny of each genotype derived from the 25 apothecia collected are presented in table 1. Also given is the maternal genotype of the 


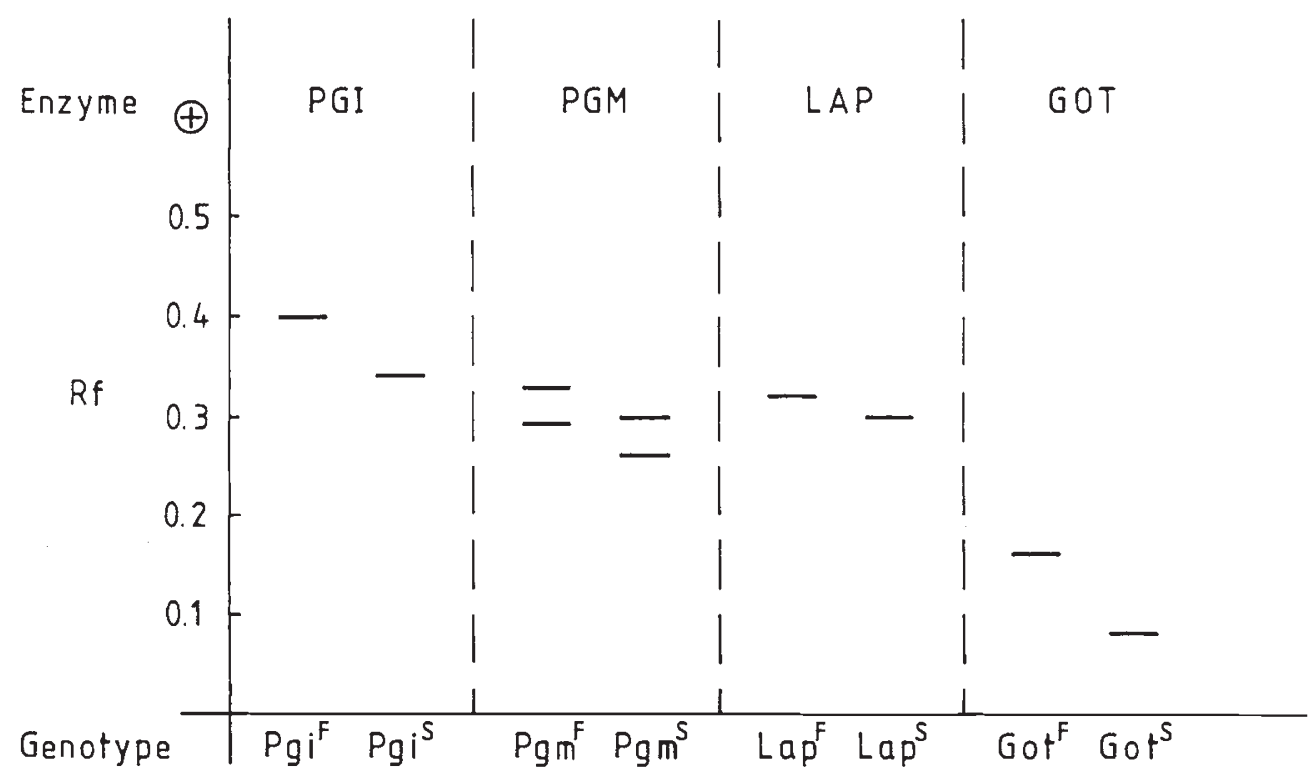

Figure 1 Isozyme banding patterns and inferred genotypes for four enzyme systems.

Table 1 Progeny genotype arrays for 25 apothecia of $C$. sororia collected from 9 lesions. Significant deviations from $1: 1$ segregation ratios among the progeny of single apothecia are indicated $\left({ }^{*} P<0.05,{ }^{* * *} P<0.001\right)$. On the right of the table are the maternal genotypes of apothecia determined experimentally $(+)$ or inferred from progeny genotype arrays $(-)$

\begin{tabular}{|c|c|c|c|c|c|c|c|c|c|c|c|c|c|}
\hline \multirow[b]{2}{*}{ Lesion } & \multirow[b]{2}{*}{ Apothecium } & \multicolumn{5}{|c|}{ Number of Progeny of each Genotype } & \multirow[b]{2}{*}{ Laps } & \multirow[b]{2}{*}{$\operatorname{Got}^{F}$} & \multirow[b]{2}{*}{$\operatorname{Got}^{\mathrm{s}}$} & \multicolumn{4}{|c|}{ Known or inferred maternal genotype } \\
\hline & & $\mathrm{Pgi}^{\mathrm{F}}$ & $\mathrm{Pgi}$ & $\mathrm{Pgm}^{\mathrm{F}}$ & $\mathrm{Pgm}^{\mathrm{S}}$ & Lap $F$ & & & & Pgi & Pgm & Lap & Got \\
\hline 1 & 1 & 0 & 23 & 23 & 0 & 0 & 23 & 14 & 9 & $\mathrm{~S}$ & $\mathrm{~F}$ & $S$ & $S+$ \\
\hline 1 & 2 & 0 & 24 & 24 & 0 & 0 & 24 & 11 & 13 & $\mathrm{~S}$ & $\mathrm{~F}$ & $\mathrm{~S}$ & $S-$ \\
\hline 1 & 3 & 0 & 23 & 23 & 0 & 0 & 23 & 2 & $21^{* * * *}$ & $\mathrm{~S}$ & $\mathrm{~F}$ & $\mathrm{~S}$ & $S-$ \\
\hline 1 & 4 & 0 & 24 & 24 & 0 & 0 & 24 & 3 & $21^{* * *}$ & $\mathrm{~S}$ & $\mathrm{~F}$ & $\mathrm{~S}$ & $S-$ \\
\hline 1 & 5 & 0 & 24 & 24 & 0 & 3 & $21^{* * *}$ & 13 & 11 & $\mathrm{~S}$ & $\mathrm{~F}$ & $S$ & $\mathrm{~F}-$ \\
\hline 2 & 1 & 0 & 22 & 22 & 0 & 0 & 22 & 10 & 12 & $S$ & $F$ & $S$ & $S-$ \\
\hline 2 & 2 & 0 & 23 & 23 & 0 & 0 & 23 & 13 & 9 & $\mathrm{~S}$ & $\mathrm{~F}$ & $\mathrm{~S}$ & $\mathrm{~F}+$ \\
\hline 2 & 3 & 0 & 24 & 24 & 0 & 12 & 12 & 12 & 12 & $\mathrm{~S}$ & $\mathrm{~F}$ & $\mathrm{~F}$ & $\mathrm{~F}+$ \\
\hline 2 & 4 & 0 & 23 & 23 & 0 & 11 & 12 & 15 & 8 & $\mathrm{~S}$ & $\mathrm{~F}$ & $\mathrm{~F}$ & $\mathrm{~F}-$ \\
\hline 2 & 5 & 0 & 22 & 15 & 7 & 13 & 9 & 17 & $5^{*}$ & $\mathrm{~S}$ & $\mathrm{~S}$ & $\mathrm{~F}$ & $\mathrm{~F}-$ \\
\hline 3 & 1 & 0 & 23 & 10 & 13 & 11 & 12 & 10 & 13 & $\mathrm{~S}$ & $S$ & $\mathrm{~F}$ & $S-$ \\
\hline 3 & 2 & 0 & 22 & 11 & 11 & 0 & 22 & 9 & 13 & $\mathrm{~S}$ & S & S & $\mathrm{S}-$ \\
\hline 3 & 3 & 0 & 24 & 13 & 11 & 0 & 24 & 13 & 11 & $\mathrm{~S}$ & $S$ & $S$ & $\mathrm{~F}-$ \\
\hline 3 & 4 & 0 & 24 & 10 & 14 & 0 & 24 & 0 & 24 & $\mathrm{~S}$ & $S$ & $S$ & $S+$ \\
\hline 3 & 5 & 0 & 22 & 11 & 11 & 2 & $20 * * *$ & 6 & $16^{*}$ & $\mathrm{~S}$ & $\mathrm{~S}$ & $S$ & $\mathrm{~S}-$ \\
\hline 4 & 1 & 10 & 13 & 23 & 0 & 12 & 11 & 20 & $3 * * *$ & $F$ & $\mathrm{~F}$ & $\mathrm{~F}$ & $\mathrm{~F}-$ \\
\hline 4 & 2 & 0 & 24 & 24 & 0 & 0 & 24 & 11 & 13 & $\mathrm{~S}$ & $\mathrm{~F}$ & $S$ & S- \\
\hline 4 & 3 & 0 & 24 & 24 & 0 & 7 & $17^{*}$ & 12 & 12 & $\mathrm{~S}$ & $\mathrm{~F}$ & $\mathrm{~S}$ & $\mathrm{~F}-$ \\
\hline 4 & 4 & 0 & 22 & 22 & 0 & 0 & 22 & 10 & 12 & $\mathrm{~S}$ & $F$ & $\mathrm{~S}$ & $S-$ \\
\hline 5 & 1 & 0 & 22 & 22 & 0 & 10 & 12 & 5 & $17^{*}$ & $\mathbf{S}$ & $F$ & $F$ & S- \\
\hline 5 & 2 & 0 & 21 & 21 & 0 & 10 & 11 & 13 & 8 & $\mathrm{~S}$ & $\mathrm{~F}$ & $\mathrm{~F}$ & $\mathrm{~F}-$ \\
\hline 6 & 1 & 0 & 20 & 20 & 0 & 7 & 13 & 12 & 8 & $\mathrm{~S}$ & $\mathrm{~F}$ & $F$ & $\mathrm{~F}-$ \\
\hline 7 & 1 & 0 & 23 & 14 & 9 & 0 & 23 & 23 & 0 & $\mathrm{~S}$ & $\mathrm{~F}$ & $S$ & $\mathrm{~F}+$ \\
\hline 8 & 1 & 0 & 22 & 12 & 10 & 0 & 22 & 0 & 22 & $\mathrm{~S}$ & $S$ & $S$ & $S-$ \\
\hline 9 & 1 & 0 & 23 & 23 & 0 & 0 & 23 & 14 & 9 & $\mathrm{~S}$ & $\mathrm{~F}$ & S & $\mathrm{F}-$ \\
\hline
\end{tabular}


apothecium where this is available. All apothecia show segregation at one or more loci. This implies that the mating system of $C$. sororia is predominantly outcrossing. Further information can be derived from the data by fitting appropriate genetic models. These can be used to generate expected progeny genotype arrays, which are compared with the observed arrays to test the validity of the genetic models.

When analysing the mating system in more detail two questions are of interest. The first concerns the number of microconidial genotypes involved in fertilisation of a single apothecium. If only one microconidial genotype is involved in the formation of ascogenous hyphae, all ascospores from one apothecium are the meiotic products of a single diploid genotype. If, on the other hand, many different microconidial genotypes are involved in fertilisation, progeny derived from a single apothecium will be the meiotic products of a diverse array of diploid genotypes.

The second question which we can ask about the mating system is whether there is any evidence for self-fertilisation occurring in the production of ascogenous hyphae. To explore these two questions we test the predictions of two simple mating models described below.

\section{MODEL A}

The assumptions of the model are:

(a) Ascogenous hyphae within an apothecium are derived from fertilisation by a single microconidial genotype.

(b) The fungus is exclusively heterothallic. Selffertilisation does not occur.

(c) Outcrossing between genotypes is random.

If the population is polymorphic for alleles $A_{1}$ and $A_{2}$ at frequencies $p_{1}$ and $p_{2}$ respectively, then the expected frequencies of apothecial types and their progeny segregation ratios are:

\begin{tabular}{lll}
$\begin{array}{l}\text { Apothecial } \\
\text { type }\end{array}$ & $\begin{array}{l}\text { Progeny segregation } \\
\text { ratio } A_{1}: A_{2}\end{array}$ & $\begin{array}{l}\text { Frequency of } \\
\text { apothecial type }\end{array}$ \\
\hline$A_{1} \times A_{1}$ & $1: 0$ & $p_{1}^{2}$ \\
$A_{1} \times A_{2}$ & $1: 1$ & $2 p_{1} p_{2}$ \\
$A_{2} \times A_{2}$ & $0: 1$ & $p_{2}^{2}$
\end{tabular}

The model predicts that if apothecia show segregation, progeny genotypes should be found in a $1: 1$ ratio, and these results should be homogeneous over apothecia. Analysis of the data in table 1 shows that 8 of the 25 apothecia scored show significant deviations from a $1: 1$ segregation ratio for at least one of the isozyme loci. Furthermore, segregation ratios are significantly heterogeneous among apothecia for loci LAP and GOT $(P<0.001$ in both cases, table 2$)$.

A second prediction of the model is that the maximum frequency of apothecia showing segregation should be 0.5 (where $p_{1}=p_{2}=0.5$ ). This maximum expected frequency is clearly exceeded for locus GOT $(P<0.001)$ where 22 of the 25 apothecia scored show segregation.

Taken together, these analyses indicate that model $A$ does not adequately describe the mating system of $C$. sororia. We must therefore consider a model in which the assumptions of fertilisation of each apothecium by a single microconidial genotype, and the absence of self-fertilisation are relaxed.

\section{MODEL B}

The assumptions of the model are:

(a) Ascogenous hyphae within a single apothecium arise through fertilisation by a large number of microconidial genotypes.

(b) A proportion of ascospores $(s)$ are produced from ascogenous hyphae which originate from self-fertilisation.

Table 2 Analysis of progeny segregation ratios from apothecia showing segregation at the isozyme loci indicated. $\chi^{2}$ tests are used to investigate both deviations from a $1: 1$ ratio when data are pooled over apothecia, and heterogeneity of segregation ratios among apothecia $(* * * P<0 \cdot 001)$

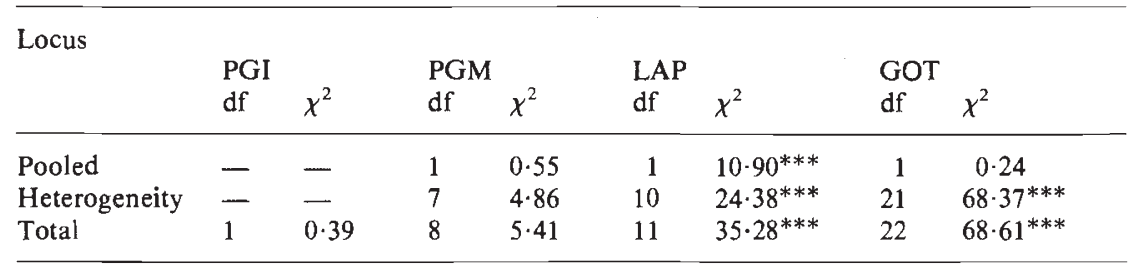


(c) The remaining proportion of ascospores $t=$ $(l-s)$ are derived from ascogenous hyphae produced by random outcrossing with a pool of outcross microconidial genotypes.

If the outcross microconidial pool is polymorphic at a diallelic locus with alleles $A_{1}$ and $A_{2}$ at frequencies $p_{1}$ and $p_{2}$ respectively, then the expected frequencies of ascospore progeny from known apothecial maternal genotypes are:

\begin{tabular}{lll} 
Apothecial maternal genotype & \multicolumn{2}{l}{ Progeny genotype } \\
\hline & $\mathrm{A}_{1}$ & $\mathrm{~A}_{2}$ \\
$\mathrm{~A}_{1}$ & $1-\mathrm{tp}_{2} / 2$ & $\mathrm{tp}_{2} / 2$ \\
$\mathrm{~A}_{2}$ & $\mathrm{tp}_{1} / 2$ & $1-\mathrm{tp}_{1} / 2$
\end{tabular}

Outcrossing rate $t$ and microconidial allele frequency $p_{1}$ can be jointly estimated from the data in table 1 by following the procedure set out in the Appendix. A maximum likelihood technique is used to assign maternal genotypes to apothecia (where these are not known) on the basis of progeny genotype arrays. It is then a simple matter to estimate $t$ and $p_{1}$ from comparison of observed and expected progeny genotype arrays.

The maximum likelihood estimates of $t$ and their standard errors are given for those loci where sufficient data are available (table 3 ). Also included is a multilocus estimate of $t$ which uses joint results from the three loci and is based on a comparison between the observed and expected numbers of discernible outcross events (modified after Shaw et al., 1981). Estimates of $t$ either do not differ from, or are significantly greater than $t=1 \cdot 0$, the value expected where all fertilisation takes place by random outcrossing. Thus there is no evidence for any significant self-fertilisation occurring in the $C$. sororia population. However, the fact that values of $t$ significantly larger than 1 are obtained suggests that the model may not provide an adequate description of the mating process.

In order to investigate which assumptions of the model are likely to be invalid we may compare model predictions with the observed data. One prediction made by the model is that where out-

Table 3 Single locus and multilocus estimates of outcrossing rate $t$ and its standard error using procedures outlined in the appendix. Significant deviations from $t=1.0$ are indicated $\left({ }^{* * *} P<0.001\right)$

\begin{tabular}{lll}
\hline Locus & $\hat{t}$ & SE $\hat{t}$ \\
\hline PGM & 1.075 & 0.081 \\
LAP & $1 \cdot 107$ & 0.071 \\
GOT & $1.316^{* * *}$ & 0.079 \\
Multilocus & $1 \cdot 187^{* * *}$ & 0.044 \\
\hline
\end{tabular}

Table $4 \chi^{2}$ tests for heterogeneity of segregation ratios among apothecia with the same inferred maternal genotype $\left.{ }^{* *} P<0.01 ;{ }^{* * *} P<0.001\right)$

\begin{tabular}{lrc}
\hline $\begin{array}{l}\text { Apothecial } \\
\text { maternal genotype }\end{array}$ & df & Heterogeneity $\chi^{2}$ \\
\hline Pgm $^{\mathrm{S}}$ & 6 & $4 \cdot 15$ \\
$\mathrm{Lap}^{\mathrm{F}}$ & 8 & $5 \cdot 82$ \\
$\mathrm{Got}^{\mathrm{F}}$ & 11 & $26 \cdot 71^{* *}$ \\
$\mathrm{Got}^{\mathrm{S}}$ & 12 & $52 \cdot 53^{* * *}$ \\
\hline
\end{tabular}

cross microconidial genotypes are randomly dispersed through the population, and each apothecium is fertilised by many microconidia from this pool, progeny segregation ratios from apothecia with the same maternal genotype should be homogeneous.

For loci PGM and LAP this prediction is upheld (table 4). However, for locus GOT, segregation ratios of progeny from identical maternal genotypes are significantly heterogeneous $(P<$ 0.001 for both maternal genotypes, table 4 ). In addition, segregation ratios tend to approach the values $1: 0,1: 1$ and $0: 1$ expected under model $A$, where only one microconidial genotype is involved in fertilisation, rather than conform to the segregation ratios expected under model $\mathrm{B}$. This analysis suggests that microconidial genotypes involved in fertilisation are not randomly distributed throughout the population, and that only a small number of microconidial genotypes (close to one) are involved in fertilisation of each apothecium. Such deviations from the assumptions of model B may help to account for the fact that estimates of $t$ greater than 1.0 have been obtained.

\section{Genetic differentiation among lesions}

Table 5 gives the frequency of the fast migrating allele for loci PGM, LAP and GOT for ascopores derived from lesions 1 to 4 . A high proportion of the total apothecia present on these lesions was sampled so that these results reflect ascospore

Table 5 Frequency of fast migrating alleles in ascospore populations derived from lesions 1 to 4 . Significance of differences in allele frequency among lesions, and $G_{S T}$, a measure of the extent of genetic differentiation, are shown $\left({ }^{* * *} P<\right.$ 0.001 )

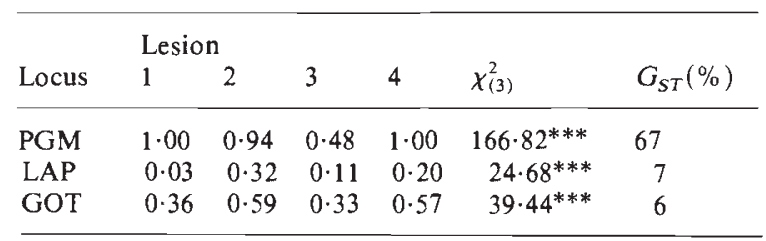


genotype frequencies from the complete lesion. There are highly significant differences in allele frequency among ascospores produced from different lesions $(P<0.001$ for all loci). The extent of genetic differentiation among these subpopulations of ascospores is very high (mean $G_{S T}=27$ per cent). This result implies that the $C$. sororia population is highly genetically subdivided. It is composed of a large number of genetically heterogeneous subpopulations, each consisting of a small number of genotypes, occupying different lesions on host trees.

\section{Linkage disequilibrium}

The results of $\chi^{2}$ tests for association between alleles at loci PGM, LAP and GOT are given in table 6. Also shown are the standardised measures of linkage disequilibrium $D^{1}=D / D_{\max }$. Calculations have been carried out both for the inferred maternal genotype generation, and for the ascospore generation. There is highly significant linkage disequilibrium between loci LAP and GOT. It is well known that linkage disequilibrium may be generated by pooling results derived from subpopulations which differ in allele frequencies, but which themselves show no linkage disequilibrium (Nei and Li, 1973). Since we already have extensive evidence of allele frequency differences among subpopulations, and since the results from these subpopulations have been pooled to calculate $D^{1}$, it is likely that the linkage disequilibrium observed is an artifact of the genetic structure of the population, and does not result from epistatic interactions between the loci.

Table $6 \chi^{2}$ tests for association between alleles at loci PGM, LAP and GOT in apothecial maternal population and ascospore population. Standardised measures of linkage disequilibrium between loci $D^{1}=D / D_{\max }$ are also given $\left({ }^{*} P<0.05 ; * * P<0.01\right)$

\begin{tabular}{llll}
\hline Locus pair & Population & $\chi_{(1)}^{2}$ & $D^{1}(\%)$ \\
\hline PGM and LAP & Apothecia & $1 \cdot 28$ & 10 \\
& Ascospore & $1 \cdot 36$ & 1 \\
PGM and GOT & Apothecia & $3 \cdot 11$ & 19 \\
& Ascospore & $0 \cdot 11$ & 1 \\
LAP and GOT & Apothecia & $5 \cdot 0^{*}$ & 35 \\
& Ascospore & $8 \cdot 26^{* *}$ & 6 \\
\hline
\end{tabular}

\section{DISCUSSION}

The work described above illustrates how studies of isozyme variation can be employed to extend our knowledge of the mating systems of fungal pathogens. The first result to emerge is that sexual reproduction in $C$. sororia takes place through outcrossing, and there is no evidence of any significant level of self-fertilisation in the population. This information could not have been obtained by more traditional approaches because it has so far proved impossible to induce fruiting of $C$. sororia in culture. It is probable that outcrossing is enforced by a single locus diallelic sexual incompatibility system similar to those which have been described in a number of other ascomycete fungi (Whitehouse, 1949; Raper, 1966).

The second conclusion that has been reached is that more than one microconidial genotype can be involved in producing ascogenous hyphae within a single apothecium of $C$. sororia. In this study, a minimum of 8 of the 25 apothecia investigated had been fertilised by more than one microconidial genotype. Laboratory studies have indicated that it is possible for more than one male nucleus to be involved in producing ascogenous hyphae within the fruiting body of an ascomycete (Nakamura and Egashira, 1961; Anagnostakis, 1982b). The present study reveals that this can occur in natural populations.

Although the mixed mating model used in this analysis has proved extremely useful, two assumptions of the model appear to be violated. Microconidial genotypes are not randomly dispersed over apothecia, and the number of different microconidial genotypes involved in the fertilisation of apothecia is probably small. Both violations of model assumptions could be accounted for by restricted dispersal of microconidia. If fertilisation is only possible between fungal genotypes which are in close proximity on a single lesion, microconidial genotypes will clearly be non-randomly dispersed to apothecia. In such circumtances only a small number of fungal genotypes will be capable of acting as male parents for a single apothecium. This number will be further reduced if a sexual incompatability system is present as suggested above. When the number of microconidial parents is low (close to one) the ascospores derived from a single apothecium will tend to be related as full-sibs, not as half-sibs as would be predicted by the mixed mating model.

The $C$. sororia population investigated in this study is composed of numerous subpopulations occupying discrete lesions. Allele frequencies differ significantly among ascospore populations derived from these lesions. These genetic differences among subpopulations may well have arisen by chance, rather than through natural selection. During colonisation of a wound by ascospores 
only a small number of fungal genotypes will establish. As a result of sampling error, lesion subpopulations are likely to differ from one to another in allele frequency. Following fertilisation within lesions, ascospore populations differing significantly in allele frequency will be produced from different lesions.

Our current understanding of breeding systems and the genetic structure of fungal pathogen populations is woefully inadequate. As this and a number of other studies have demonstrated, much can be revealed by a careful analysis of naturally occurring isozyme variation (Burdon and Roelfs, 1985b: Shattock et al., 1986). Information of this nature is essential if we wish not only to understand the evolution of fungal pathogens, but also to manage fungal disease.

Acknowledgements We are grateful to the Forestry Commission for permission to sample from the Black Wood of Rannoch. This research was supported by a grant from the Natural Environment Research Council to R.A.E.

\section{REFERENCES}

ANAGNOSTAKIS, S. L. 1977. Vegetative incompatibility in Endothia parasitica. Exp. Mycol., 1, 306-316.

ANAGNOSTAKIS, S. L. $1982 a$. Genetic analyses of Endothia parasitica: linkage data for four single genes and three vegetative compatibility types. Genetics, 102, 25-28.

ANAGNOSTAKIS, S. L. $1982 b$. The origin of ascogeneous hyphae in Endothia parasitica. Genetics, 100, 413-416.

BATKO, S. AND PAWSEY, R. G. 1964. Stem canker of pine caused by Crumenula sororia. Trans. Br. Mycol. Soc., 47, 257-261.

BERNIER, L., JENG, R. S. AND HUBBES, M. 1983. Differentiation of aggressive and non-aggressive isolates of Ceratocystis ulmi by gel electrophoresis of intramycelial enzymes. Mycotaxon, 17, 456-472.

BRASIER, C. M. 1970. Variation in a natural population of Schizophyllum commune. Am. Nat., 104, 191-204.

BRASIER, C. M. 1984. Inter-mycelial recognition systems in Ceratocystis ulmi: their physiological properties and ecological importance. In Jennings, D. H. and Rayner, A. D. M. (eds.) The ecology and physiology of the fungal mycelium, British Mycological Society Symposium 8, Cambridge University Press, Cambridge.

BROWN, A. H. D., BARRETT, S. C. H. AND MORAN, G. F. 1985. Mating system estimation in forest trees: models, methods and meanings. In Gregorius, H.-R. (ed.) Population Genetics in Forestry, Springer-Verlag, Berlin.

BROWN, A. H. D., MATHESON, A. C. AND ELDRIDGE, K. G. 1975. Estimation of the mating system of Eucalyptus obliqua L'Herit by using allozyme polymorphisms. Aust. J. Bot., 23, 931-949.

BURDON, J. J. AND MARSHALL, D. R. 1981. Isozyme variation between species and formae speciales of the genus Puccinia Pers. Can. J. Bot. 59, 2628-2634.

BURDON, J. J. AND MARSHALL, D. R. 1983. The use of isozymes in plant disease research. In Tanksley, S. D. and Orton, T. J. (eds.) Isozymes in Plant Genetics and Breeding, Elsevier, Amsterdam.
BURDON, J. J., MARSHALL, D. R. AND LUIG, N. H. 1981. Isozyme analysis indicates that a virulent cereal rust pathogen is a somatic hybrid. Nature, 293, 565-566.

BURDON, J. J., MARSHALL, D. R., LUIG, N. H. AND GOW, D. J. S. 1982. Isozyme studies on the origin and evolution of Puccinia graminis f. sp. tritici in Australia. Aust. J. Biol. Sci., 35, 231-238.

BURDON, J. J. AND ROELFS, A. P. $1985 a$. Isozyme and virulence variation in asexually reproducing populations of Puccinia graminis and $P$. recondita on wheat. Phytopath., 75, 907913.

BURDON, J. J. AND ROELFS, A. P. $1985 b$. The effect of sexual and asexual reproduction on the isozyme structure of populations of Puccinia graminis. Phytopath., 75, 1068-1073.

BURNETT, J. H. 1956. The mating systems of fungi I. New Phytol., 55, 50-90.

BURNETT, J. H. 1965. The natural history of recombination systems. In Esser, K. and Raper, J. R. (eds.) Incompatability in Fungi, Springer, Berlin.

CLEGG, M. T. 1980. Measuring plant mating systems. Bioscience, $30,814-818$

GROVES, J. W. 1969. Crumenulopsis, a new name to replace Crumenula Rehm. Can. J. Bot., 47, 47-51.

HAYES, A. J. 1975. Some preliminary observations on the distribution of Crumenula sororia spores in the atmosphere. Trans. Br. Mycol. Soc., 64, 546-550.

JINKS, J. L., CATEN, C. E., SIMCHEN, G. AND CROFT, J. H. 1966. Heterokaryon incompatibility and variation in wild populations of Aspergillus nidulans. Heredity, 21, 227-239.

MANAP, A. M. A. AND hayes, A. J. 1971. Crumenula sororia Karst. associated with cankering and dieback of Corsican pine. Scottish Forestry, 25, 185-200.

NAKAMURA, K. AND EGASHIRA, T. 1961. Genetically mixed perithecia in Neurospora. Nature, 190, 1129-1130.

NEI, M. AND LI, W. H. 1973. Linkage disequilibrium in subdivided populations. Genetics, 75, 213-219.

NEWTON, A. C. AND CATEN, C. E. 1985. Variation for isozymes and double-standard RNA among isolates of Puccinia striiformis and two other cereal rusts. Plant Path., 34, 235247.

OLD, K. M., MORAN, G. F. AND BELL, J. C. 1984. Isozyme variability among isolates of Phytophthora cinnamomi from Australia and Papua New Guinea. Can. J. Bot., 62, 20162022.

PERKINS, D. D., TURNER, B. C. AND BARRY, E. G. 1976. Strains of Neurospora collected from nature. Evolution, 30, 281313.

RAPER, J. R. 1966. Life cycles, basic patterns of sexuality, and sexual mechanisms. In Ainsworth, G. C. and Sussman, A. S. (eds.) The Fungi Vol II, Academic Press, New York.

RAYNER, A. D. M. AND TURTON, M. N. 1982. Mycelial interactions and population structure in the genus Stereum: $S$. rugosum, $S$. sanguinolentum and $S$. rameale. Trans. Br. Mycol. Soc., 78, 483-493.

ROELFS, A. P. AND GROTH, J. V. 1980. A comparison of virulence phenotypes in wheat stem rust populations reproducing sexually and asexually. Phytopath., 70, 855-862.

SHATTOCK, R. C., TOOLEY, P. W. AND FRY, W. E. 1986. Genetics of Phytophthora infestans: Determination of recombination, segregation and selfing by isozyme analysis. Phytopath., 76, 410-413.

SHAW, D. V., KAHLER, A. L. AND ALLARD, R. W. 1981. A multilocus estimator of mating system parameters in plant populations. Proc. Natl. Acad. Sci. U.S.A., 78, 1298-1302.

SPEITH, P. T. 1975. Population genetics of allozyme variation in Neurospora intermedia. Genetics, 80, 785-805. 
STENLID, J. 1985. Population studies of Heterobasidion annosum as determined by somatic incompatibility, sexual incompatibility and isoenzyme patterns. Can. J. Bot., 63, 2268-2273.

VALLEJOS, C. E. 1983. Enzyme activity stains. In Tanksley, S. D. and Orton, T. J. (eds.) Isozymes in Plant Genetics and Breeding, Elsevier, Amsterdam.

VAN Vloten, H. AND GREMmen, J. 1953. Studies in the discomycete genera Crumenula De Not. and Cenangium Fr. Acta Botan. Neerl, 2, 226-241.

WHITEHOUSE, H. L. K. 1949. Heterothallism and sex in the fungi. Biol. Rev., 24, 411-447.

\section{APPENDIX}

The procedure outlined below follows closely that given by Brown et al. (1975) for the analysis of mating systems in diploid higher plants. The procedure has been adapted for use where maternal and progeny genotypes are haploid.

According to mating model $B$ ascogenous hyphae within a single apothecium arise following fertilisation by a large number of microconidial genotypes. A proportion of ascospores $s$ are produced by ascogenous hyphae which originate from self-fertilisation. The remaining proportion $t=$ $(l-s)$ are derived from ascogneous hyphae which result from random outcrossing with a microconidial pool. If the outcross microconidial population is polymorphic at a diallelic locus with alleles $A_{1}$ and $A_{2}$ at frequencies $p_{1}$ and $p_{2}$ respectively, the conditional probability of obtaining an ascospore of genotype $j$ given an apothecial maternal genotype $i$ is:

\begin{tabular}{|c|c|c|}
\hline $\begin{array}{l}\text { Apothecial } \\
\text { maternal genotype (i) }\end{array}$ & Progeny & enotype $(j)$ \\
\hline $\begin{array}{l}A_{1} \\
A_{2}\end{array}$ & $\begin{array}{l}A_{1} \\
\left(l-t p_{2} / 2\right)=u_{1} \\
\left(t p_{1} / 2\right)=v_{1}\end{array}$ & $\begin{array}{l}A_{2} \\
\left(t p_{2} / 2\right)=u_{2} \\
\left(l-t p_{1} / 2\right)=v_{2}\end{array}$ \\
\hline
\end{tabular}

\section{(a) Determination of maternal genotype of apothecium}

Suppose that we observe $r$ ascospore progeny of genotype $A_{1}$ among a total of $n$ progeny derived from a single apothecium. The probabilities of obtaining this progeny genotype array from a given apothecial maternal genotype are:

Apothecial Probability of obtaining maternal genotype (i) genotype array

$\begin{array}{ll}A_{1} & \left(\begin{array}{l}n \\ r\end{array}\right) u_{1}^{r} u_{2}^{n-r} \\ A_{2} & \left(\begin{array}{l}n \\ r\end{array}\right) v_{1}^{r} v_{2}^{n-r}\end{array}$

$A_{1}$ is the more likely parent when:

$$
r \log \left(\frac{u_{1}}{v_{1}}\right)+(n-r) \log \left(\frac{u_{2}}{v_{2}}\right)>0
$$

Trial values of $t$ and $p_{1}$ are used to make the initial determination of maternal genotype. In this study the trial values were $t=1 \cdot 0$ and $p_{1}$ was taken as the frequency of allele $A_{1}$ in ascospore progeny. After calculation of $t$ and $p_{1}$ from (b) below, these were substituted in the formulae above to redetermine maternal genotypes. This process was continued until there were no changes in the inferred maternal genotypes after substitution of $t$ and $p_{1}$ values.

\section{(b) Joint estimation of $t$ and $p_{1}$}

For convenience we make the following tranformations:

$$
X=t p_{2} / 2 \quad \text { and } \quad Y=t p_{1} / 2
$$

Suppose that $N_{1}$ progeny are scored from apothecia of maternal genotype $A_{1}$, and $O_{1}$ progeny of genotype $A_{2}$ are found. $N_{2}$ progeny from apothecia of maternal genotype $A_{2}$ yield $\mathrm{O}_{2}$ progeny of genotype $A_{1}$. Observed and expected frequencies of these discernible outcross events are:

\begin{tabular}{lll} 
Apothecial maternal genotype & $\begin{array}{l}\text { Frequency } \\
\text { outcrosses } \\
\text { Observed }\end{array}$ & Expected \\
\hline$A_{1}$ & $O_{1} / N_{1}$ & $X$ \\
$A_{2}$ & $O_{2} / N_{2}$ & $Y$
\end{tabular}

Maximum likelihood estimates of $X$ and $Y$ and their variances are:

$$
\begin{array}{ll}
\hat{X}=O_{1} / N_{1} & \operatorname{var}(\hat{X})=\hat{X}(1-\hat{X}) / N_{1} \\
\hat{Y}=O_{2} / N_{2} & \operatorname{var}(\hat{Y})=\hat{Y}(1-\hat{Y}) / N_{2}
\end{array}
$$

Maximum likelihood estimates of $t$ and $p_{1}$ and their variances are:

$$
\begin{gathered}
\hat{t}=2(\hat{X}+\hat{Y}) \quad \operatorname{var}(\hat{t})=4(\operatorname{var}(\hat{X})+\operatorname{var}(\hat{Y})) \\
\hat{p}_{1}=\left(\frac{\hat{Y}}{\hat{Y}+\hat{X}}\right) \\
\operatorname{var}\left(\hat{p}_{1}\right) \simeq\left(\hat{p}_{1}\right)^{2}\left(\frac{\operatorname{var}(\hat{Y})}{Y^{2}}+\frac{\operatorname{var}(\hat{Y})+\operatorname{var}(\hat{X})}{(\hat{X}+\hat{Y})^{2}}\right. \\
\left.-\frac{2 \operatorname{var}(\hat{Y})}{\hat{Y}(\hat{X}+\hat{Y})}\right)
\end{gathered}
$$

